\title{
Rasta Resin-DMAP and Its Use as a Recyclable Catalyst for the Addition of Carbon Dioxide to Epoxides
}

\author{
Jinni Lu and Patrick H. Toy* \\ Department of Chemistry, The University of Hong Kong, Pokfulam Road, Hong Kong, P. R. of China \\ Fax +852 28571586; E-mail: phtoy@hku.hk \\ Received:
}

\begin{abstract}
Rasta resin-DMAP, a new heterogeneous polystyrenebased amine, has been synthesized and used as a catalyst in addition reactions of carbon dioxide to epoxides to afford cyclic carbonate products. This new material was found to be a more efficient catalyst than divinyl benzene cross-linked polystyrene supported DMAP, and was readily recovered and reused without significant loss of catalytic activity.
\end{abstract}

Key words: polymer-supported organocatalyst, polystyrene, DMAP, carbon dioxide, cyclic carbonate

A great number of organic polymers in a wide variety of formats have been used for reagent and catalyst immobilization. ${ }^{1}$ For example, the rasta resin architecture, which is characterized by a heterogeneous cross-linked polystyrene core onto which linear polystyrene grafts are attached (Figure 1), was first introduced a decade ago. ${ }^{2}$ Since then it has been used as the basis for several polymer-supported reagents and catalysts. ${ }^{3}$ Recently we have reported a phosphine $(\mathbf{1})^{4}$ and a bifunctional phosphine/amine analogue (2) ${ }^{5}$ that were efficient reagents in one-pot Wittig reactions, and a phosphonium salt $(3)^{6}$ that catalyzed carbonyl cyanosilylation reactions, that were all based on the rasta resin concept. Importantly, in our studies of $\mathbf{1}$ and $\mathbf{3}$ we found that locating the functional groups on the flexible and solvent accessible grafts allowed these materials to be more efficient at mediating the desired reactions than were similar polymer-supported phosphines and phosphonium salts based on the Merrifield resin architecture of polystyrene lightly cross-linked with divinyl benzene. In addition to our interest in polymer-supported phosphines, ${ }^{7,8}$ we have also studied polymer-supported 2,2'-bipyridine ${ }^{9}$ and 4(dimethylamino)pyridine (DMAP), ${ }^{10}$ and thus wanted to see if the rasta resin architecture would also serve as an improved heterogeneous platform for DMAP in organocatalytic applications. Thus, herein we report the synthesis of rasta resinDMAP (4), and its use as a catalyst in the addition of carbon dioxide to epoxides to form cyclic carbonates. ${ }^{11-15}$

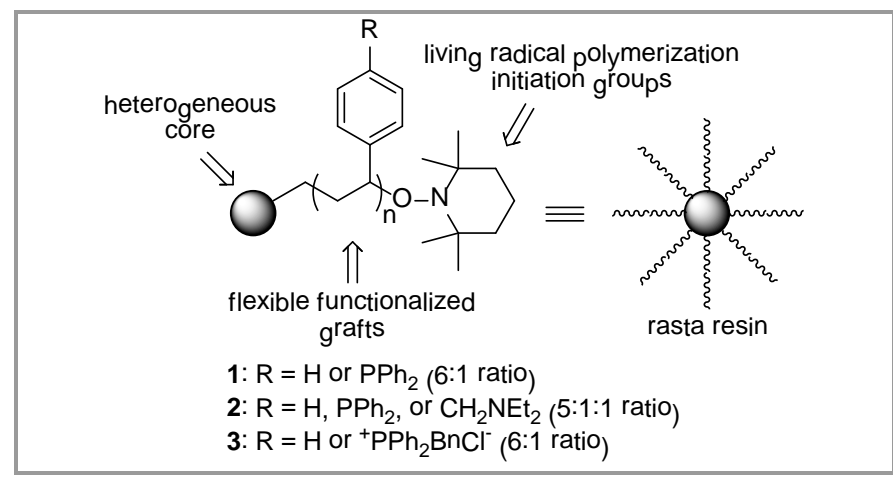

Figure 1 The rasta resin concept
Polymer 4 was synthesized from JandaJel-based ${ }^{16}$ core $\mathbf{5}$ as shown in Scheme 1. Core $\mathbf{5}$ was prepared as previously reported $^{5}$ and then heated in the presence of DMAP monomer $\mathbf{6}^{10}$ and styrene (for flexibility) in cumene to add the functioalized grafts, and afford $4 .{ }^{17}$ Elemental analysis was used to determine the DMAP loading level of 4 to be $1.08 \mathrm{mmol} / \mathrm{g}$, and SEM analysis was conducted to compare the size and morphology of $\mathbf{5}$ and $\mathbf{4}$. As can be seen in Figure 2 (scale: 1 $\mathrm{cm}=100 \mathrm{~mm}$ ) both 5 (Figure 2a) and $\mathbf{4}$ (Figure 2B) are generally spherical in shape, and the latter grew to be much larger in diameter than its precursor.

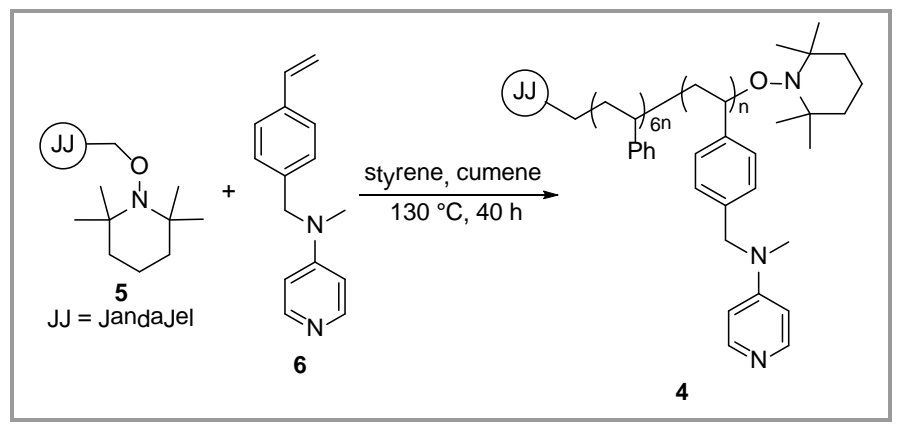

Scheme 1 Synthesis of 4
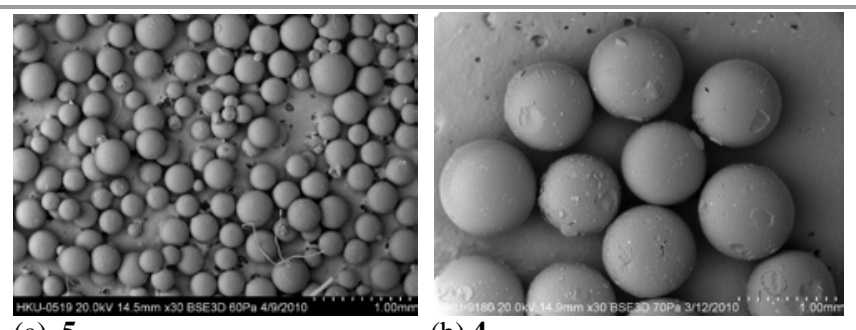

(a) 5 (b) 4

Figure 2 SEM images

To assess the utility of $\mathbf{4}$ in the carbon dioxide addition reactions we chose propylene oxide (7a) as the substrate for optimization reactions (Table 1 ). Using identical reaction conditions, 0.004 equivalents of $\mathbf{4}$ afforded slightly lower yield of carbonate 8a than did DMAP, but higher yield than did a commercially available $2 \%$ divinyl benzene cross-linked polystyrene (entries 1-3). Unfortunately it was observed that in the absence of a solvent, product formation was much less efficient (entry 4), and that THF afforded less satisfactory results (entry 5) than did $\mathrm{CH}_{2} \mathrm{Cl}_{2}$. The influence of the $\mathrm{CO}_{2}$ atmosphere pressure on reaction efficiency was also examined. Low conversion of 7a to 8a was obtained at 10 bar, and increasing the pressure to 40 bar did not result in a significant increase in product yield (entries 6-9). Thus, it appears that 20-30 bar is minimum necessary pressure for efficient reactions, and therefore subsequent reactions were performed using a pressure of 30 bar. Furthermore, we noted that the use of 
0.01 equivalents of $\mathbf{4}$ afforded slightly higher yield in less time (entry 8 vs. entry 3), and thus this catalyst loading level was used in subsequent reactions.

Table 1 Optimization of reactions catalyzed by 4

\begin{tabular}{ccccccc}
\hline & & & & \\
& & & & & \\
\hline
\end{tabular}

${ }^{a}$ Reaction conditions: 7a (1.3 g, $\left.22.4 \mathrm{mmol}\right)$, catalyst (0.4 mol \%) and solvent $(0.5 \mathrm{~mL})$ heated at $120{ }^{\circ} \mathrm{C}$ under an atmosphere of $\mathrm{CO}_{2}$ at the indicated pressure.

${ }^{b}$ Result using a commercially available PS-DMAP (0.4 mol \%) as the catalyst.

${ }^{\mathrm{c}}$ Results using $1 \mathrm{~mol} \%$ of 4 .

With the optimal reaction conditions determined, we next examined the general utility of $\mathbf{4}$, and the results of these experiments are summarized in Table $2 .^{18}$ Monosubstituted epoxides 7a-f (entries 1-6) provided satisfying results, and 1,1disubstituted epoxide $\mathbf{7 g}$ (entry 7 ) afforded moderate yield of the desired cyclic carbonate $\mathbf{8 g}$ after a prolonged reaction time. However, only low yield of the product $\mathbf{8 h}$ was formed from the reaction of 1,2-disubstituted epoxide $7 \mathbf{h}$, even after $40 \mathrm{~h}$ (entry 8), and cyclohexene oxide (7i) and cyclooctene oxide (7j) affored only trace amounts of the corresponding cyclic carbonates $\mathbf{8 i}$ and $\mathbf{8 j}$ in similar reactions (entries 9-10). It should be noted that these reactivity trends mirror what has been reported previously for similar reaction substrates and catalysts. ${ }^{11,12}$ For the sake of comparison, commercially available heterogeneous PS-DMAP was used as the catalyst for substrates $\mathbf{7 e}$ and $\mathbf{7 d}$. However, as with $\mathbf{7 a}$, it but proved to be less efficient than $\mathbf{4}$ with both of these substrates (entries 4 and 5).

Table 2 Carbon dioxide addition reactions catalyzed by $\mathbf{4}$

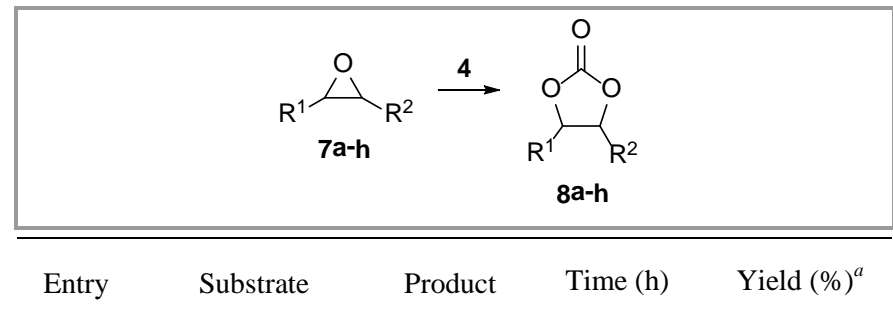

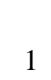

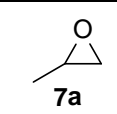

$\mathbf{8 a}$

1

91

2<smiles>CCC1CO1</smiles>

8b

1

90

3<smiles>CCCCC1CO1</smiles>

8c<smiles>Cl[C]C1CO1</smiles>

8d

1

89

4<smiles>C1O[PbH]1</smiles>

8e<smiles>[TlH]c1ccccc1</smiles>

8f

3<smiles>CC1(C)CO1</smiles>

$8 \mathrm{~g}$

8<smiles>c1ccc([C@@H]2O[PH2+]2c2ccccc2)cc1</smiles>

8h

40<smiles>C1CC2OC2C1</smiles>

$8 \mathbf{i}$

40

trace

10<smiles>C1CCC2OC2CC1</smiles>

8j

94

5
${ }^{a}$ Reaction conditions: 7a-j (22.4 mmol), $4(0.224 \mathrm{mmol})$ and $\mathrm{CH}_{2} \mathrm{Cl}_{2}$ $(0.5 \mathrm{~mL})$ heated at $120{ }^{\circ} \mathrm{C}$ under an atmosphere of $\mathrm{CO}_{2}$ at 30 bar.

${ }^{\mathrm{b}}$ Results using commercially available PS-DMAP as the catalyst.

Once the general utility of $\mathbf{4}$ was demonstrated in the carbonate synthesis reactions, we next examined its recyclability. After each cycle the polymer was filtered, washed with $\mathrm{CH}_{2} \mathrm{Cl}_{2}$ and dried. As can be seen in Table 3, no significant decrease in the activity of $\mathbf{4}$ in the conversion of 7a to 8a was observed, even in the $8^{\text {th }}$ reaction cycle. The polymer beads became darker in color after reactions, but this visual change did not seem to affect their catalytic efficiency. This strongly indicated that the rasta resin-supported DMAP catalyst is highly stable even under high temperature and pressure reaction conditions, allowing for it to be readily recovered and reused.

Table 3 Recycling of 4

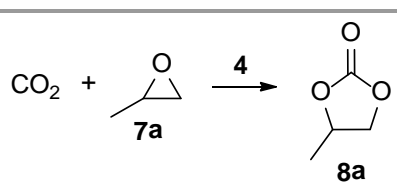




\begin{tabular}{|c|c|c|c|c|c|c|c|c|}
\hline Cycle & 1 & 2 & 3 & 4 & 5 & 6 & 7 & 8 \\
\hline Yield (\%) & 92 & 92 & 91 & 91 & 91 & 90 & 87 & 87 \\
\hline
\end{tabular}

A possible mechanism for the addition reactions catalyzed by 4 that is based on what has been reported previously in the literature $^{11}$ is outlined in Scheme 2. The low yields observed in Table 2, entries 8-10 can be explained by steric hindrance of the epoxide, which retards nucleophilic attack by the catalyst.

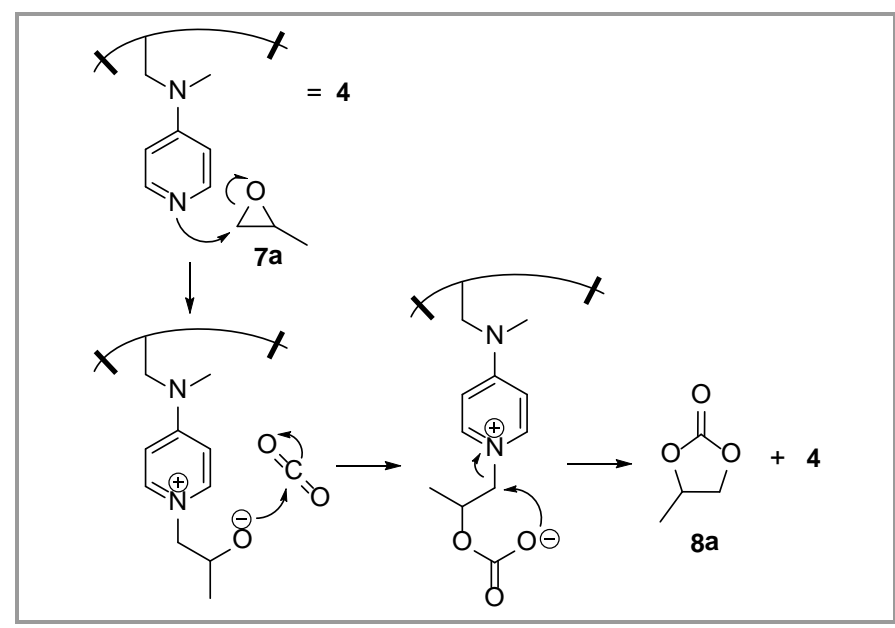

Scheme 2 Possible mechanism of carbon dioxide addition reactions mediated by 4

In conclusion, we have synthesized a new heterogeneous polymer-supported DMAP material that is a highly efficient organocatalyst for the addition of carbon dioxide to epoxides to form the corresponding cyclic carbonates. Our studies indicate that the use of the rasta resin architecture in $\mathbf{4}$ allows it to be a better catalyst in these reactions than does typical commercially available heterogeneous polystyrene-supported DMAP that is based on the Merrifield resin architecture. Furthermore, $\mathbf{4}$ is robust and amenable for use at high temperature and under high pressure. Thus, it was readily recovered and reused in our reactions. Additional applications of this novel polymer are currently being examined, such as in the DMAPcatalyzed alkyne isomerization reaction, ${ }^{19}$ and other recently reported DMAP-mediated processes, ${ }^{20}$ and results from these studies will be reported shortly.

Supporting Information for this article is available online at http://www.thieme-connect.com/ejournals/toc/synlett.

\section{Acknowledgement}

This research was supported financially by the University of Hong Kong and the Research Grants Council of the Hong Kong S. A. R, P. R. of China (Project No. HKU 704108P).

\section{References and Notes}

(1) Lu, J.; Toy, P. H. Chem. Rev. 2009, 109, 815.

(2) Hodges, J. C.; Harikrishnan, L. S.; Ault-Justus, S. J. Comb. Chem. 2000, 2, 80.
(3) (a) Lindsley, C. W.; Hodges, J. C.; Filzen, G. F.; Watson, B. M.; Geyer, A. G. J. Comb. Chem. 2000, 2, 550. (b) McAlpine, S. R.; Lindsley, C. W.; Hodges, J. C.; Leonard, D. M.; Filzen, G. F. J. Comb. Chem. 2001, 3, 1. (c) Wisnoski, D. D.; Leister, W. H.; Strauss, K. A.; Zhao, Z.; Lindsley, C. W. Tetrahedron Lett. 2003, 44, 4321. (d) Fournier, D.; Pascual, S.; Montembault, V.; Haddleton, D. M.; Fontaine, L. J. Comb. Chem. 2006, 8, 522. (e) Fournier, D.; Pascual, S.; Montembault, V.; Fontaine, L. J. Polym. Sci. A: Polym. Chem. 2006, 44, 5316. (f) Pawluczyk, J. M.; McClain, R. T.; Denicola, C.; Mulhearn, J. J. Rudd, D. J.; Lindsley, C. W. Tetrahedron Lett. 2007, 48, 1497. (g) Chen, G.; Tao, L.; Mantovani, G.; Geng, J.; Nystroem, D.; Haddleton, D. M. Macromolecules 2007, 40, 7513.

(4) Leung, P. S.-W.; Teng, Y.; Toy, P. H. Synlett 2010, 1997.

(5) Leung, P. S.-W.; Teng, Y.; Toy, P. H. Org. Lett. 2010, 12, 4996.

(6) Teng, Y.; Toy, P. H. Submitted for publication.

(7) For our work regarding cross-linked polymers, see: (a) Kwok, M.; Choi, W.; He, H. S.; Toy, P. H. J. Org. Chem. 2003, 68, 9831. (b) Zhao, L. J.; He, H. S.; Shi, M.; Toy, P. H. J. Comb. Chem. 2004, 6, 680. (c) Zhao, L.-J.; Kwong, C. K.-W.; Shi, M.; Toy, P. H. Tetrahedron 2005, 61, 12026.

(8) For our work regarding non-cross-linked polymers, see: (a) Harned, A. M.; He, H. S.; Toy, P. H.; Flynn, D. L.; Hanson, P. R. J. Am. Chem. Soc. 2005, 127, 52. (b) He, H. S.; Yan, J. J.; Shen, R.; Zhuo, S.; Toy, P. H. Synlett 2006, 563. (c) Kwong, C. K.-W.; Fu, M. Y.; Law, H. C.-H.; Toy, P. H. Synlett 2010, 2617.

(9) Chung, C. W. Y.; Toy, P. H. J. Comb. Chem. 2007, 9, 155.

(10) Kwong, C. K.-W.; Huang, R.; Zhang, M.; Shi, M.; Toy, P. H. Chem. Eur. J. 2007, 13, 2369.

(11) For selected reviews regarding the addition of carbon dioxide to epoxides to form cyclic carbonates, see: (a) Dai, W.-L.; Luo, S.-L.; Yin, S.-F.; Au, C.-T. Appl. Catal., A 2009, 366, 2. (b) Sakakura, T.; Kohno, K. Chem. Commun. 2009, 1312. (c) North, M.; Pasquale, R.; Young, C. Green Chem. 2010, 12, 1514-1539.

(12) For the organocatalytic addition of carbon dioxide to epoxides, see: (a) Shiels, R. A.; Jones, C. W. J. Mol. Catal. A Chem. 2007, 261, 160 and references cited therein. (b) Qi, C.; Jiang, H.; Wang, Z.; Zou, B.; Yang, S. Synlett 2007, 255. (c) Barkakaty, B.; Morino, K.; Sudo, A.; Endo, T. Green Chem. 2010, 12, 42.

(13) For selected reviews regarding polymer-supported organocatalysts, see: Benaglia, M.; Puglisi, A.; Cozzi, F. Chem. Rev. 2003, 103, 3401. (b) Benaglia, M. New J. Chem. 2006, 30, 1525. (c) Cozzi, F. Adv. Synth. Catal. 2006, 348, 1367. (d) Gruttadauria, M.; Giacalone, F.; Noto, R. Chem. Soc. Rev. 2008, 37, 1666. (e) Kristensen, T. E.; Hansen, T. Eur. J. Org. Chem. 2010, 3179.

(14) For the use of polymer-supported organocatalysts in the addition of carbon dioxide to epoxides, see: (a) Xie, H.; Duan, H.; Li, S.; Zhang, S. New J. Chem. 2005, 29, 1199. (b) Du, Y.; Wang, J.-Q.; Chen, J.-Y.; Cai, F.; Tian, J.-S.; Kong, D.-L.; He, L.-N. Tetrahedron Lett. 2006, 47, 1271. (c) Jagtap, S. R.; Raje, V. P.; Samant, S. D.; Bhanage, B. M. J. Mol. Catal. A Chem. 2007, 266, 69. (d) Qi, C.-R.; Jiang, H.-F.; Wang, Z.-Y.; Zou, B. Chin. J. Chem. 2007, 25, 10511054. (e) Qi, C.; Ye, J.; Zeng, W.; Jiang, H. Adv. Synth. Catal. 2010, 352, 1925.

(15) For the use of other polymers, such as ion exchange resins, polyaniline salts and immobilized ionic liquids, to catalyze the addition of carbon dioxide to epoxides, see: (a) Du, Y.; Cai, F.; Kong, D.-L.; He, L.-N. Green Chem. 2005, 7, 518. (b) He, J.; Wu, T.; Zhang, Z.; Ding, K.; Han, B.; Xie, Y.; Jiang, T.; Liu, Z. Chem. Eur. J. 2007, 13, 6992. (c) Xie, Y.; 
Zhang, Z.; Jiang, T.; He, J.; Han, B.; Wu, T.; Ding, K. Angew. Chem. Int. Ed. 2007, 46, 7255.

(16) (a) Toy, P. H.; Janda, K. D. Tetrahedron Lett. 1999, 40, 6329. (b) Toy, P. H.; Reger, T. S.; Janda, K. D. Aldrichimica Acta. 2000, 33, 87. (c) Toy, P. H.; Reger, T. S.; Garibay, P.; Garno, J. C.; Malikayil, J. A.; Liu, G.-Y.; Janda, K. D. J. Comb. Chem. 2001, 3, 117. (d) Choi, M. K. W.; Toy, P. H. Tetrahedron 2004, 60, 2903.

(17) See Supporting Information for details.

(18) General Procedure for $\mathrm{CO}_{2}$ Addition Reactions Epoxide $7 \mathbf{a}-\mathbf{j}$ ( $22.4 \mathrm{mmol}), \mathrm{CH}_{2} \mathrm{Cl}_{2}(0.5 \mathrm{mmol})$ and $\mathbf{4}$ $(0.224 \mathrm{mmol})$ were placed in a $25 \mathrm{ml}$ stainless-steel autoclave. Carbon dioxide was then introduced into the reactor at an initial pressure of $20 \mathrm{bar}$ at room temperature. The reactor was then heated to $120^{\circ} \mathrm{C}$ and the pressure was adjusted to 30 bar. The reaction mixture was stirred under these conditions for indicated time, and then the autoclave was cooled using an ice bath. After releasing the pressure, the $\mathbf{4}$ was filtered off and washed with $\mathrm{CH}_{2} \mathrm{Cl}_{2}$. The filtrate was concentrated in vacuo to afford the product $\mathbf{8 a}-\mathbf{j}$. The identity of the products was confirmed by ${ }^{1} \mathrm{H}-\mathrm{NMR}$.

(19) Yue, Y.; Yu, X.-Q.; Pu, L. Chem. Eur. J. 2009, 15, 5104.

(20) (a) Bollini, M.; González, M.; Bruno, A. M. Tetrahedron Lett. 2009, 50, 1507. (b) Ko, K.; Nakano, K.; Watanabe, S.; Ichikawa, Y.; Kotsuki, H. Tetrahedron Lett. 2009, 50, 4025. (c) Deb, I.; Shanbhag, P.; Mobin, S. M.; Namboothiri, I. N. N. Eur. J. Org. Chem. 2009, 4091. (d) Mhasni, O.; Rezgui, F. Tetrahedron Lett. 2010, 51, 586. (e) Naidu, K. C.; Babu, G. R.; Gangaiah, L.; Mukkanti, K.; Madhusudhan, G. Tetrahedron Lett. 2010, 51, 1226. (f) Angelini, T.; Fringuelli, F.; Lanari, D.; Pizzo, F.; Vaccaro, L. Tetrahedron Lett. 2010, 51, 1566. (g) Goncalves, S.; Nicolas, M.; Wagner, A.; Baati, R. Tetrahedron Lett. 2010, 51, 2348. (h) Aoki, S.; Kotani, S.; Sugiura, M.; Nakajima, M. Tetrahedron Lett. 2010, 51, 3547. (i) Hudhomme, P. Synlett 2010, 1331. (j) Vuluga, D.; Legros, J.; Crousse, B.; Bonnet-

Delpon, D. Chem. Eur. J. 2010, 16, 1776. (k) Helou, M.; Miserque, O.; Brusson, J.-M.; Carpentier, J.-F.; Guillaume, S. M. Chem. Eur. J. 2010, 16, 13805. 
Graphical abstract

$$
\text { RR-DMAP = a recyclable heterogeneous catalyst }
$$

